6. Трупак Н.Г. Замораживание горных пород при проходке стволов. - М.: Углетехиздат, 1954. - 896 с.: ил.

7. Трупак Н.Г. Замораживание грунтов при сооружении вертикальных шахтных стволов. - М.: Недра, 1983. - 270 с.: ил.

8. Harris J.S. Ground freezing in practice. - Thomas Telford Limited, 1995. - 264 p.

9. Левин Л.Ю., Семин М.А., Зайцев А.В. Калибровка теплофизических свойств породного массива при моделировании формирования ледопородного ограждения строящихся шахтных стволов // Физикотехнические проблемы разработки полезных ископаемых. - 2019. - № 1. - С. 172-184.

10. Иудин М.М. Обеспечение безопасности устойчивости ствола при оттаивании ледопородного ограждения // Вестник Якутского государственного университета. - 2009. - Т. 6., № 1. - С. 46-50.

11. Кузина А.В. Систематизация причин повреждений замораживающих колонок при строительстве глубоких вертикальных стволов с использованием метода искусственного замораживания // Горн. информ.аналит. бюл. - 2006. - № 11. - С. 396-402.

12. Паланкоев И.М. Оценка степени риска возникновения аварийных ситуаций при строительстве вертикальных шахтных стволов способом искусственного замораживания // Горн. информ.-аналит. бюл. - 2013. - № 6. - С. 44-51.

13. Тарасов В.В., Пестрикова В.С. Обзор аварийных ситуаций, возникших на Верхнекамском калийном месторождении при проходке шахтных стволов // Горн. информ.-аналит. бюл. - 2015. - № 5. - С. 23-29.

14. Паланкоев И.М. Обоснование параметров технологии проходки шахтных стволов в искусственно замороженных породах: дис. ... к.т.н.; 25.00.22., 25.00.20 / Паланкоев Ибрагим Магомедович. - М. 2015. - 189 с.

15.ЕвроХим - Годовые отчеты за 2014-2017: [Офиц. сайт]. - Режим доступа: URL: https://www.eurochemgroup.com/investors/reports-results/ (дата обращения: 22.07.2019).

16. Головатый И.И., Левин Л.Ю., Паршаков О.С., Диулин Д.А. Оптимизация процессов формирования ледопородного ограждения при сооружении шахтных стволов // Горн. журн. - 2018. - № 8. - С. 48-53. DOI: $10.17580 /$ gzh.2018.08.06.

17. Вакуленко И.С., Николаев П.В. Анализ и перспективы развития способа искусственного замораживания горных пород в подземном строительстве // Горн. информ.-аналит. бюл. - 2015. - № 3. - С. 338-346.

18. Хайден Т.В., Вегнер Б. Современная технология замораживания пород на примере двух объектов, находящихся на стадии строительства, состоящих из пяти вертикальных шахтных стволов // Горн. журн. - 2014. - № 9. - С. 65-67.

19. Шуплик М.Н., Плохих В.А., Никифоров К.П., Киселев В.Н. Перспективы замораживания грунтов в подземном строительстве // Подземное пространство мира. - 2001. - № 4. - С. 28-38.

20. Левин Л.Ю., Семин М.А., Паршаков О.С. Совершенствование методов прогнозирования состояния ледопородного ограждения строящихся шахтных стволов с использованием распределенных измерений температуры в контрольных скважинах // Записки Горного института. - 2019. - Т. 237, № 3. - С. 268-274. DOI: 10.31897/PMI.2019.3.268.

21. Паршаков О.С., Левин Л.Ю., Плехов О.А., Пантелеев И.А. Экспериментальные измерения температуры породного массива с использованием оптоволоконной технологии для анализа формирования ледопородного ограждения шахтных стволов // Материалы XI Международного симпозиума по проблемам инженерного мерзлотоведения: тез. докл. конф. / Ин-т мерзлотоведения СО РАН. - Якутск, 2017. - С. 292-293.

22. Паршаков О.С. Контроль и управление состоянием ледопородных ограждений при строительстве шахтных стволов // Стратегия и процессы освоения георесурсов: сб. науч. тр. Вып. 16 / ГИ УрО РАН. Пермь, 2018. - С. 266-271. DOI: 10.7242/gdsp.2018.16.72.

\title{
НОРМАЛИЗАЦИЯ ТЕПЛОВОГО РЕЖИМА ГЛУБОКИХ ЗАЛЕЖЕЙ РУДНИКА «ТАЙМЫРСКИЙ» ДО МОМЕНТА ВВОДА СИСТЕМЫ КОНДИЦИОНИРОВАНИЯ
}

\author{
Д.С. КОРМщИКОВ ${ }^{1,2}$, М.Д. ПОПОВ ${ }^{2}$ \\ ${ }^{1}$ Горный институт УрО РАН, г. Пермь \\ ${ }^{2} \mathrm{OOO} « H П О$ «АэроСфера», г. Пермь
}

\begin{abstract}
Аннотация. В статье рассмотрены способы нормализации теплового режима глубоких залежей на примере рудника «Таймырский» ПАО «Норильский Никель». Разработана комбинация методов нормализации теплового режима позволяющая снизить температуру воздуха в рабочей зоне без применения системы кондиционирования. Проведено численное моделирование распределения теплоты на сети горных выработок залежей C-3 и С-4 с использованием разработанного способа нормализации температуры. Сделан вывод о возможности применения данного способа.
\end{abstract}

Ключевые слова: рудник, шахта, микроклимат, нормализация температуры, тепловой режим, безопасность, моделирование, система кондиционирования, аэросеть. 


\section{Введение}

Рост глубины ведения горных работ в совокупности с применением высокопроизводительной техники при добыче полезных ископаемых приводит к росту температуры воздуха в рабочих зонах рудников [1].

На проектируемых горизонтах залежей C-3 и C-4 рудника «Таймырский» глубина ведения горных работ превышает 1600 метров. На такой глубине температура пород массива в естественных условиях превышает $+40{ }^{\circ} \mathrm{C}$, что в совокупности с применением высокопроизводительного добычного и транспортного оборудованием приводит к превышению температуры воздуха, поступающего на проветривания рабочих зон.

Согласно требованиям пункта 156 «Правил безопасности при ведении горных работ и переработке твердых полезных ископаемых» температура воздуха в забоях подготовительных и очистных выработок и на рабочих местах с постоянным присутствием персонала не должна превышать $+26^{\circ} \mathrm{C}$. При температуре воздуха свыше допустимой должно предусматриваться его охлаждение.

Применение систем кондиционирования для нормализации теплового режима требует больших капитальных и временных затрат. Монтаж и пусконаладка системы кондиционирования воздуха на залежах C-3, C-4 рудника «Таймырский» занимает 2 года. В это время ведение работ в пределах залежей С-3, C-4 становится невозможным без применения дополнительных технических и организационных мероприятий, снижающих температуру воздуха.

В статье рассмотрены основные организационные и технические мероприятий по обеспечению безопасных условий труда в горных выработках по микроклиматическому фактору при отработке запасов до момента ввода в эксплуатацию системы кондиционирования воздуха. Разработанные решения подтверждены моделированием тепловых процессов на залежах C-3 и C-4 рудника «Таймырский» в программном комплексе «Аэросеть» [2] .

\section{Факторы, определяющие тепловой режим}

Вклад тех или иных факторов отличается в зависимости от геологических и горнотехнических особенностей, климатических условий региона и расположения горного предприятия. Основными термодинамическими факторами, влияющими на тепловой режим глубоких рудников, являются [3]:

- влияние сезонных колебаний температуры наружного воздуха, поступающего в рудник;

- гидростатическое сжатие воздуха при его движении по воздухоподающим стволам;

- тепломассообменные процессы между рудничным воздухом и породным массивом;

- тепловыделения от техногенных источников.

Проведены исследования влияния каждого из представленных факторов на формирование микроклиматических параметров в горных выработках проектируемых участков рудника «Таймырский», в результате чего выявлены определяющие термодинамические факторы, формирующие тепловой режим рабочих зон рудника.

По результатам моделирования сезонное изменение температуры воздуха, поступающего на проветривание рудника, не оказывает существенного влияния на расстоянии более 2 км от воздухоподающего ствола. Рассматриваемые залежи находятся на значительном удалении от стволов. Этот фактор не является определяющими и не формирует тепловой режим рабочих зон в пределах залежей С-3 и С-4 рудника «Таймырский».

Так как гидростатический нагрев воздуха в пределах залежи С-3 и C-4 - явление постоянное и не подлежащее воздействию и уменьшению его отрицательного эффекта без использования средств кондиционирования, его влияние при моделировании тепловых процессов в пределах залежи С-3,4 не учитывалось.

Таким образом по результатам предварительной оценки основными факторами, которые необходимо учитывать при моделировании рассматриваемых залежей, являются теплообмен с породным массивом и техногенные источники теплоты. 


\section{Моделирование теплового режима типовых забоев}

Моделирование теплового режима рудника в целом и отдельных его залежей - трудоемкий процесс, требующий больших временных затрат и вычислительных мощностей. Поэтому на первом этапе произведены расчеты теплового режима типовых забоев с различными параметрами:

- Длина тупиковой выработки - от 50 до $500 \mathrm{M}$, с шагом $50 \mathrm{M}$.

- Количество воздуха в выработке со сквозным проветриванием - $200 \mathrm{~m}^{3} / \mathrm{c}$, $100 \mathrm{~m}^{3} / \mathrm{c}, 50 \mathrm{~m}^{3} / \mathrm{c}, 25 \mathrm{~m}^{3} / \mathrm{c}$.

- Температура входящего воздуха - от $21{ }^{\circ} \mathrm{C}$ до $29^{\circ} \mathrm{C}$, с шагом $2^{\circ} \mathrm{C}$.

Учет выделения теплоты от оборудования в забое производился по следующему графику - 12 часов работает погрузочно-доставочная машина, 12 часов работает буровая установка.

Моделирование проводилось с учетом охлаждения массива. Для этого каждые 50 метров проходки выработ-
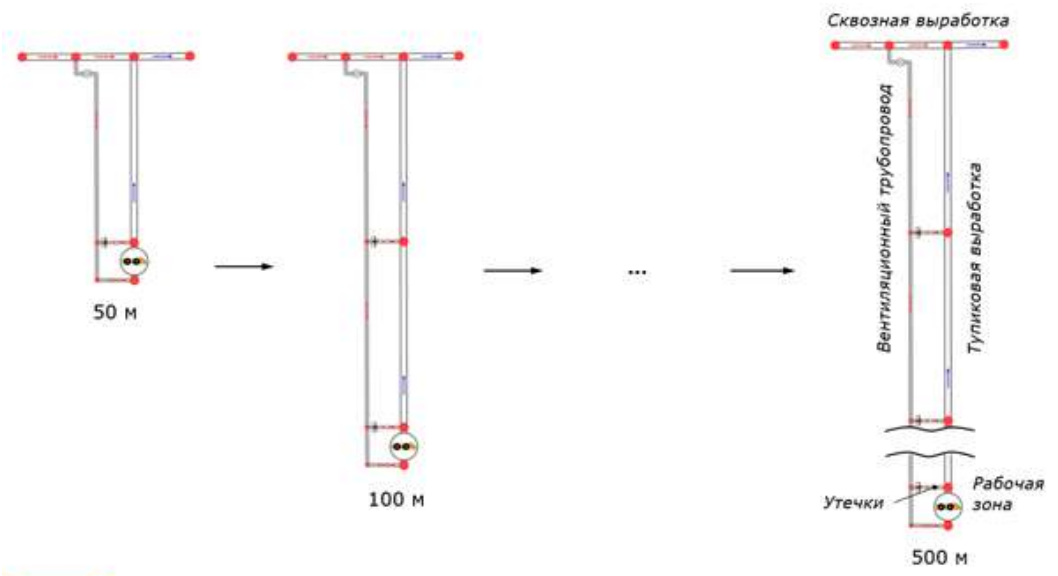

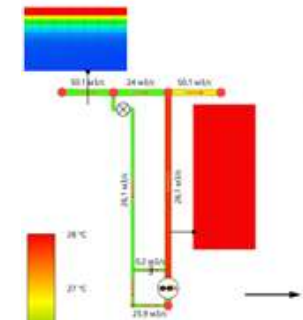

$50 \mathrm{M}-22$ дня

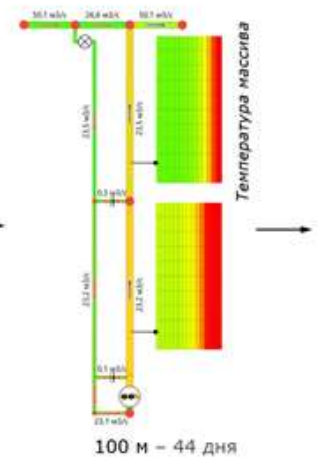

Рис. 1. Принцип построения модели

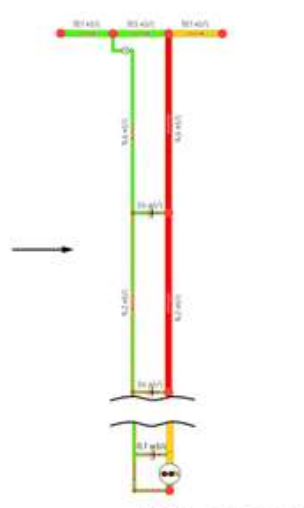

500 M - 214 дней ки охлаждались в течение 22 дней, что соответствует ориентировочному времени проходки 50 метров выработки. После чего производилось моделирование следующих 50 метров длины при различных начальных температурах воздуха на свежей струе.

Результаты моделирования каждых 50 метров выработки являлись исходными данными для последующих 50 метров. Схема построения модели приведена на рис. 1.

Результаты вариантов моделирования распределения температуры в тупиковой выработке проанализированы. На основе этих данных построены графики и определены зависимости изменения температуры воздуха в различных местах моделируемого участка от различных факторов. Данные зависимости представлены на рис. 2.
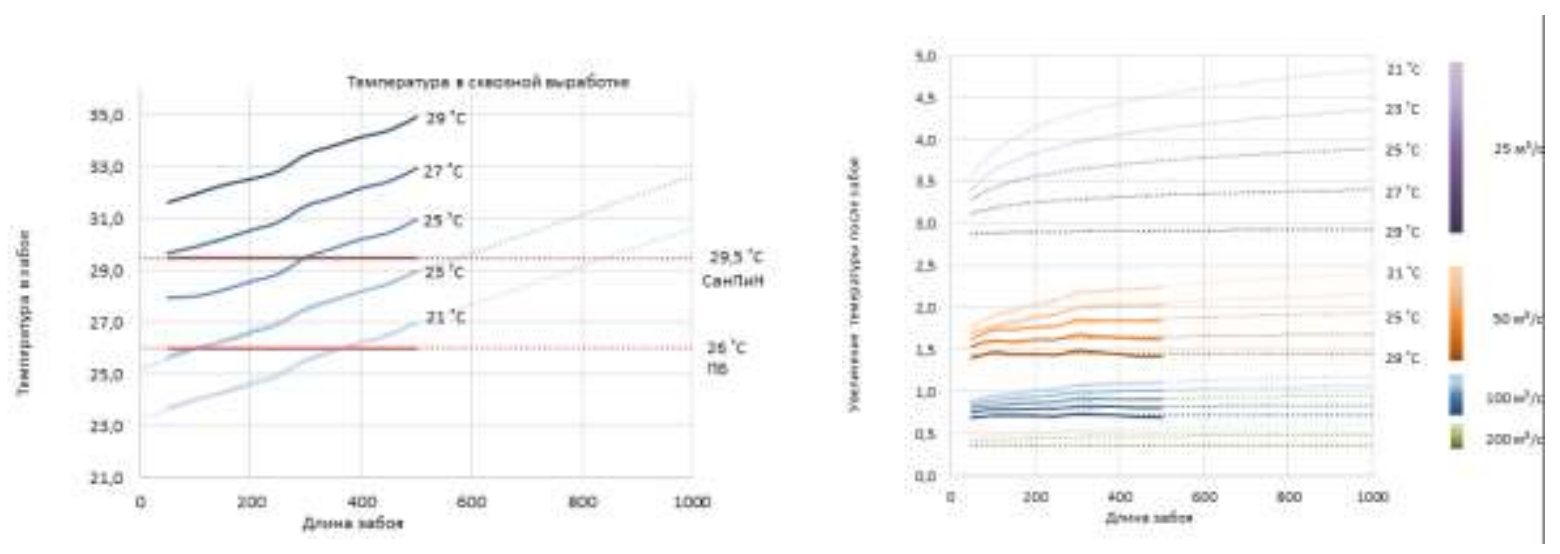

Рис. 2. Температура воздуха в сквозной и тупиковой выработке 
Используя предложенные зависимости, можно аналитически определить температуру в забое и в сквозной выработке после забоя. Применяя графики поочередно можно делать выводы следующего характера. Например, сквозная выработка с расходом воздуха $100 \mathrm{~m}^{3} / \mathrm{c}$ и температурой $21{ }^{\circ} \mathrm{C}$ сможет обеспечить последовательное проветривание трех забоев с погрузочно-доставочной машиной без превышения температуры, предусмотренной правилами безопасности. Длина проходческих выработок при этом не должна превышать 380 м, 210 м, 70 м, соответственно. В условиях необходимой производительности залежи С-3 и С-4 данное количество рабочих зон недостаточно.

\section{Способы нормализации микроклимата}

В случае отсутствия централизованной системы кондиционирования залежей следует рассматривать следующие способы организации работ в условиях повышенных температур воздуха [10]:

- Пересмотреть подход к нормированию температуры воздуха.

- Применение специальной одежды.

- Применение теплоизоляционной крепи.

- Организация воздушного душирования.

- Организация вентиляции по требованию.

- Использование машин с кондиционерами.

Применение некоторых из вышеперечисленных способов нормализации температуры воздуха являются малоэффективными или

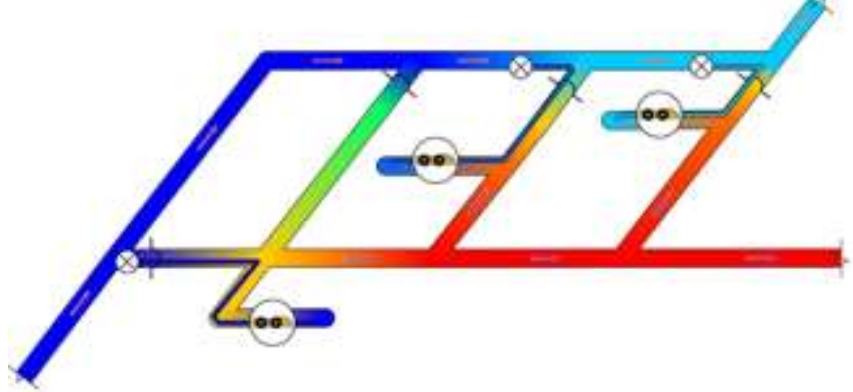

Рис. 3. Эффективное использование холодного воздуха неприменимыми в условиях рудника «Таймырский». К дальнейшему рассмотрению принята комбинация следующих методов: организация воздушного душирования, применение техники с кондиционерами и организация вентиляции по требованию. Такая комбинация позволяет эффективно использовать холодную струю воздуха. Принципиальная схема проветривания, поясняющая сугь комбинированного метода, приведена на рис. 3 .

Суть комбинированного метода заключается в подаче свежей струи воздуха по одному тракту движения с помощью изолирующих сооружений и распределении воздуха в рабочие зоны вентиляторами местного проветривания по вентиляционным трубопроводам. Это позволяет снизить нагрев воздуха при его движении к рабочей зоне. Таким образом в забоях будет обеспечена допустимая для ведения работ температура. После забоев нагрев воздуха выше допустимой температуры неизбежен. Применение шахтной самоходной техники с кабинами закрытого типа и кондиционерами позволяет транспортировать руду в зонах повышенной температуры, поскольку водитель машины будет изолирован от воздействия температуры рудничной атмосферы.

\section{Моделирование теплораспределения залежей C-3,4}

На следующем этапе работы была разработана тепловая модель залежей C-3 и C-4, учитывающая теплообмен с породным массивом и выделение теплоты от техногенных источников. На базе этой модели проведено прогнозирование микроклиматических условий в горных выработках согласно календарному плану отработки залежей C-3 и C-4 рудника «Таймырский» с учетом применения комбинации методов нормализации микроклиматических параметров горных выработок без использования системы кондиционирования. Моделирование производилось поквартально, при этом исходными данными для расчета следующего квартала являлись результаты моделирования предыдущего квартала.

По результатам моделирования сделан вывод о том, что применяемые мероприятия позволяют обеспечить допустимые параметры воздуха без применения системы кондиционирования. Так же была определена временная граница, до которой возможна отра- 
ботка запасов залежей без использования системы кондиционирования, результаты моделирования которой приведены на рис. 4.

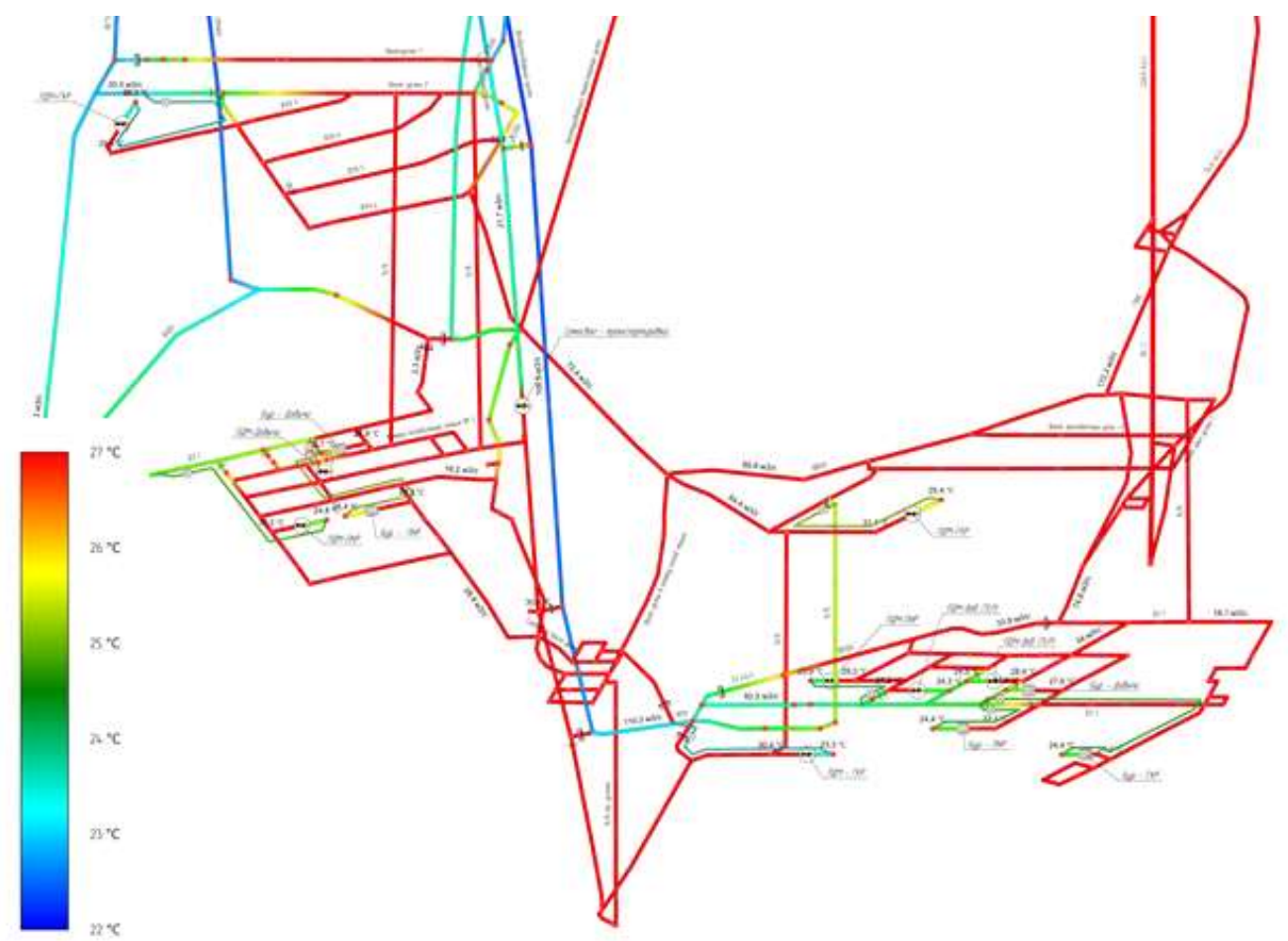

Рис. 4. Теплораспределение на залежах C-3,4 на II квартал 2020 года

Максимальное количество техники, которое может находиться в одновременной работе на залежи С-3 составляет две погрузочно-доставочные машины и три буровые установки суммарной мощностью до 430 кВт. Для залежи С-4 количество техники составляет: пять погрузочно-доставочных машин и три буровые установки, суммарная мощность которых не должна превышать 950 кВт.

\section{Выводы}

По результатам работы предложена комбинация мероприятий, позволяющая добиться допустимых температур воздуха, поступающего на проветривание рабочих зон и продолжать работы без остановки технологического процесса. Применение данных мероприятий позволило производить монтаж и пусконоладочные работы системы кондиционирования залежей C-3,4. Эффективность применения мероприятий проверена многократным моделированием распределения температуры воздуха в сети горных выработок рудника «Таймырский» в программе Аэросеть [4].

\section{БИБЛИОГРАФИЧЕСКИЙ СПИСОК}

1. Зайцев А.В. Разработка способов нормализации микроклиматических условий в горных выработках глубоких рудников: дис. ... к.т.н.; 25.00.20; защищена 21.06.2013 / Зайцев Артем Вячеславович. - Пермь, 2013. - 168 с.

2. Аналитический комплекс «АэроСеть»: программа для ЭВМ: свидетельство о гос. регистрации № 2015610589 / Зайцев А.В., Казаков Б.П., Кашников А.В., Кормщиков Д.С., Круглов Ю.В., Левин Л.Ю., Мальков П.С., Шалимов А.В.; заявитель и правообладатель ГИ УрО РАН - № 2014613790; заявл. 24.04.2014; зарегистрировано 14.01.2015; опубл. 20.02.2015. - 1 с.

3. Карелин В.Н., Кравченко А.В., Левин Л.Ю., Казаков Б.П., Зайцев А.В. Особенности формирования микроклиматических условий в горных выработках глубоких рудников // Горн. журн. - 2013. - № 6. - С. 65-68.

4. Dietterle H.B. Neue Untersuchengsergebnisse auf dem Gebiet die Grubenklimas im Kalibergbau // Neue Hutte Zeitschrift fur das Berg - und Huttenwesen. - 1961. - Nov. - Hall 11. 